\title{
Risk factors of anterior cruciate ligament injury in football players: a systematic review of the literature
}

\author{
Piero Volpi ${ }^{1,2}$ \\ Gian Nicola Bisciotti ${ }^{3}$ \\ Karim Chamari ${ }^{3}$ \\ Emanuela Cena ${ }^{3}$ \\ Giulia Carimati ${ }^{1}$ \\ Nicola Luigi Bragazzi ${ }^{4}$ \\ 1 Department of Knee Orthopaedic and Sports \\ Traumatology Unit, Humanitas Research Hospital, \\ Rozzano, (MI), Italy \\ 2 FC Internazionale Medical Staff, Milano, Italy \\ 3 Qatar Orthopaedic and Sport Medicine Hospital, \\ FIFA Center of Excellence, Doha, Qatar \\ ${ }^{4}$ Department of Health Sciences (DISSAL), \\ University of Genoa, Italy
}

\author{
Corresponding author: \\ Piero Volpi \\ Department of Knee Orthopaedic and Sports \\ Traumatology Unit, Humanitas Research Hospital, \\ Via Manzoni 56 \\ 20089 Rozzano (MI), Italy \\ E-mail: volpi.piero@libero.it
}

\section{Summary}

Background: The ACL lesion represents one of the most dramatic injuries in a sportsman's career. There are many injury risk factors related to intrinsic, or non-modifiable, and extrinsic, or modifiable, factors. In literature at today current evidence suggests that ACL injury risk is multifactorial and involves biomechanical, anatomical, hormonal and neuromuscular factors.

Purpose: To perform a systematic review of the literature concerning the $A C L$ injury risk factors in soccer.

Conclusion: The injury risk factors show a low level of evidence, further studies in the field are needed. Study design: Systematic review.

KEY WORDS: ACL, gender, age, training, genetic risk factors.

\section{Introduction}

One of the most serious events that could occur dur- ing a knee sprain is the anterior cruciate ligament (ACL) rupture. ACL tear represents, indeed, a concern, in that it could lead to osteoarthritis over a 1520 year period ${ }^{1,2}$. Furthermore, ACL injury may hamper return to play ${ }^{3}$. Given the worldwide popularity and diffusion of soccer as well as the importance of ACL injury in soccer players, understanding risk factors of ACL tear is crucial. ACL, composed of the anteromedial and posterolateral bundles, ensures tibial stability, originating from the posteromedial portion of the lateral femoral condyle and inserting slightly anterior to the tibial intercondylar eminence. Approximately one fifth of football injuries occurs at the knee joint level $^{4}$ and, moreover, ACL injury can be associated with other injuries, such as meniscal damage (in 35\% of cases), medial collateral ligament (MCL) lesion (in $6 \%$ of cases), posterior cruciate ligament tear (in $2.5 \%$ of cases), or chondral damage (in $4 \%$ of cases) ${ }^{5}$. Non-contact ACL tear generally accounts an important fraction of $A C L$ injuries, representing between 28 and $85 \%$ of all ACL lesions, on average about 50 and $58 \%$ of injuries for male and female subjects, respectively. Typical movements predisposing to noncontact ACL injuries are given by cutting, torsional movements and landing after a jump, especially if landing is carried out in the one-legged stance. However, many cases of ACL rupture are due to a disturbance of the balance caused by the opponent (i.e. a push or a disturbance of the landing phase after a jump $)^{6}$. According to Hewett et al. ${ }^{7}$, in order to explain ACL injury etiopathogenesis, four hypotheses can be formulated: 1) the ligament dominance hypothesis (muscles of lower limbs do not sufficiently absorb the ground reaction forces, so the joint and the ligaments are forced to absorb them over a reduced time period, resulting into an excessive dynamic of the knee valgus, hip adduction and hip internal rotation and, as such, jeopardizing ACL integrity); 2) the quadriceps dominance hypothesis (some athletes tend to stabilize the knee joint by primarily using the quadriceps muscles, pulling the tibia anteriorly to the femur and, thus, inducing a shear stress at ACL level); 3) the leg dominance hypothesis (during athletic tasks non requiring leg dominance, leg dominance and force asymmetry may predispose to greater risk of future ACL injury); and 4) the trunk dominance hypothesis (that is to say, the inability to precisely control the trunk in a three-dimensional space, during the execution of a given athletic task, because of growth and maturation factors). 


\section{Material and methods}

\section{Aim of the current systematic review}

The aim of the current systematic review is to systematically underpin the risk factors predisposing to ACL injury among football players, according to the Preferred Reporting Items for Systematic Reviews and Meta-analyses (PRISMA) guidelines, as well as to the "Muscle, Ligament and Tendon Journal" guidelines ${ }^{8}$.

\section{Search strategy}

Two Authors independently screened the literature, using a string of keywords such as "ACL injury", "football players" and "risk factors", properly connected by Boolean operators. When appropriate, medical subject headings $(\mathrm{MeSH})$ and wild-card options were used. Target journals were hand-searched, in order to increase the chance to get all relevant articles. For each article, the following pieces of information were extracted and recorded on an ad hoc Excel spreadsheet. Search strategy is detailed in Table I, to which the reader is kindly referred for further details.

\section{Results}

After screening 267 articles 21 have been included and synthesized in the current systematic review. Characteristics of included studies are shown in Table II.

\section{Gender}

Quisquater ${ }^{9}$ et al. found that female gender was associated with $A C L$ injury risk. This was in agree with Roos et al. ${ }^{10}$, who showed that female population resulted in an OR of $1.6(95 \% \mathrm{Cl} 1.3-2.1)$. Other studies confirmed this finding and found that interaction between female gender and another parameter was associated with higher ACL injury rate ${ }^{11-13}$. A metaanalysis carried out by Prodromos et al. ${ }^{14}$ found that female: male ratio in ACL injured football players was 2.67.

ACL injury rate is equal to 0.063 events per 1,000 hours of exposure time ${ }^{11}$, being higher among female subjects $(0.10 / 1,000$ hours of exposure match versus 0.05 among male players $)^{11,12}$.

\section{Age}

Some studies have found that age over 18 years could be considered as a risk factor of ACL injury. Allen ${ }^{15}$ et al. found that relatively older age (OR 1.5 per year; $p=0.03$ ) was associated with $A C L$ graft tear but not with contralateral ACL injury. Conversely, Roos et al. ${ }^{10}$ found that younger age was associated with higher $A C L$ injury rate.

\section{Anatomic and biomechanical factors}

Several anatomic and biomechanical factors are associated with $\mathrm{ACL}$ injury risk in the extant literature. However, few studies have rigorously assessed these relationship among $A C L$-injured football players. Söderman et al. ${ }^{16}$ found that joint laxity, low postural

Table I. Search strategy used in the study.

\begin{tabular}{ll}
\hline Search strategy items & Details \\
\hline Searched databases & PubMed/MEDLINE, Scopus, ISI \\
Searched string & ("anterior cruciate ligament" OR ACL) AND (lesion OR tear OR rupture OR injury) AND \\
& (soccer OR football) AND risk
\end{tabular}

Inclusion criteria

$\mathrm{P}$ : Articles investigating anterior cruciate ligament injuries in football players competing at any level. I: None (only observational, non-interventional studies were synthesized). C: With non-injured football players. O: Strength of the association between a risk factor and anterior cruciate ligament injury. Primary articles

Exclusion criteria

$\mathrm{P}$ : Articles investigating athletes in general and for which data relative to football players only could not be extracted. I: Articles dealing with the impact/effectiveness of prevention programs or interventions. C: With other sport disciplines. O: Articles studying risk factors of knee injury not focusing on anterior cruciate ligament rupture or for which data specifically related to anterior cruciate ligament could not be extracted; articles investigating electromyography, electromechanics, biomechanics, kinetics and kinematics of anterior cruciate ligament in non-injured football players, linking the findings with putative mechanisms of ACL injury; articles investigating tests for predicting risk factors of anterior cruciate ligament injury in football players; articles focusing on treatment and management of anterior cruciate ligament in football players from a clinical/surgical standpoint; articles studying return to play after anterior cruciate ligament injury in football players. Review articles

Time filter

None set

Language filter

None set

Target journals

American Journal of Sports Medicine; British Journal of Sports Medicine 


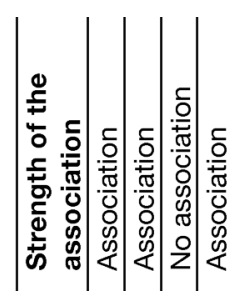

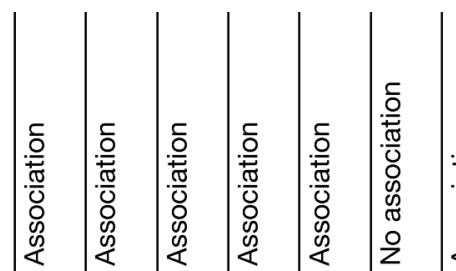

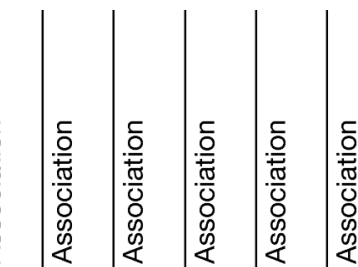

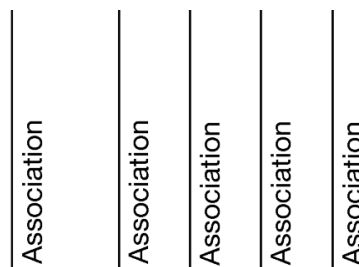

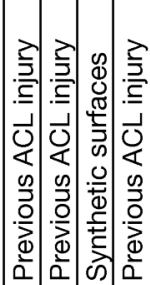

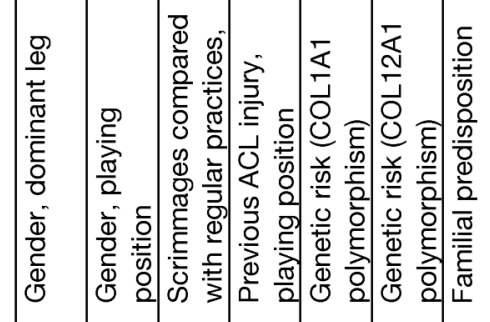

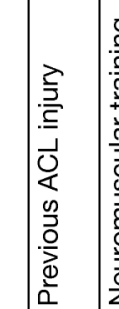

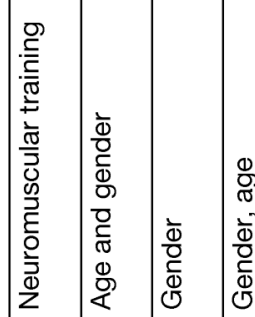

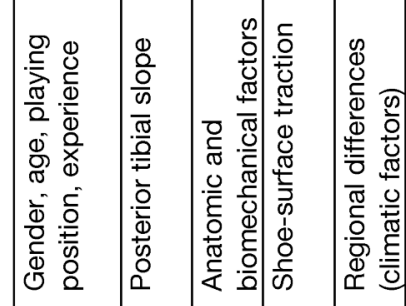

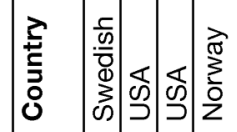

क्ष

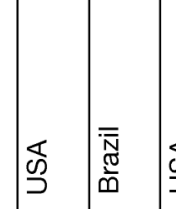

\)

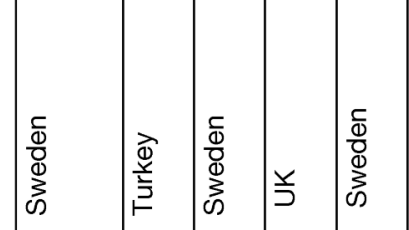
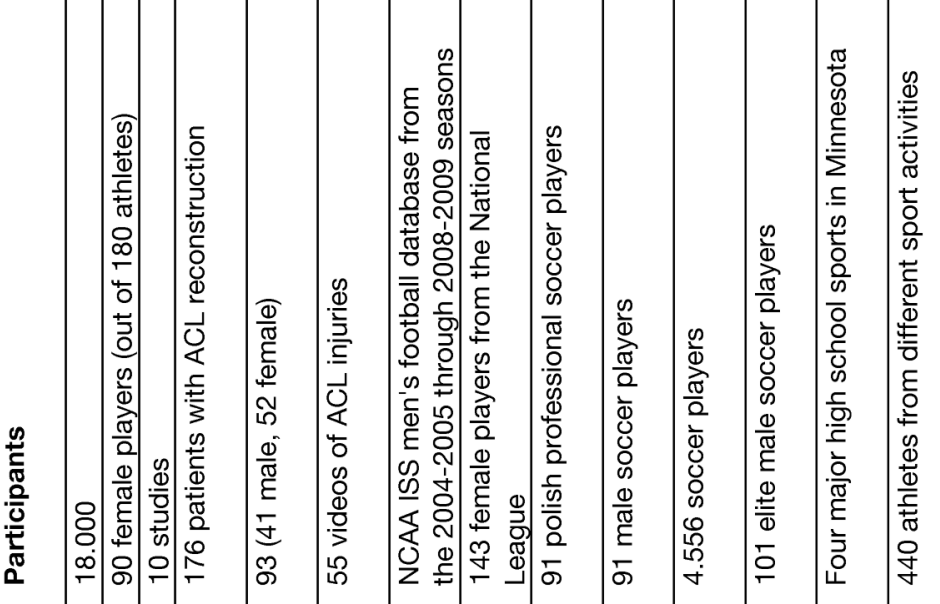

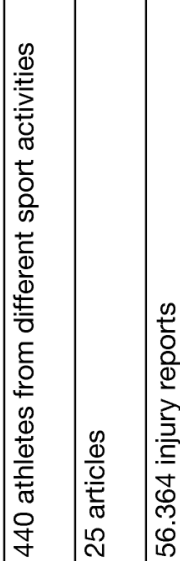
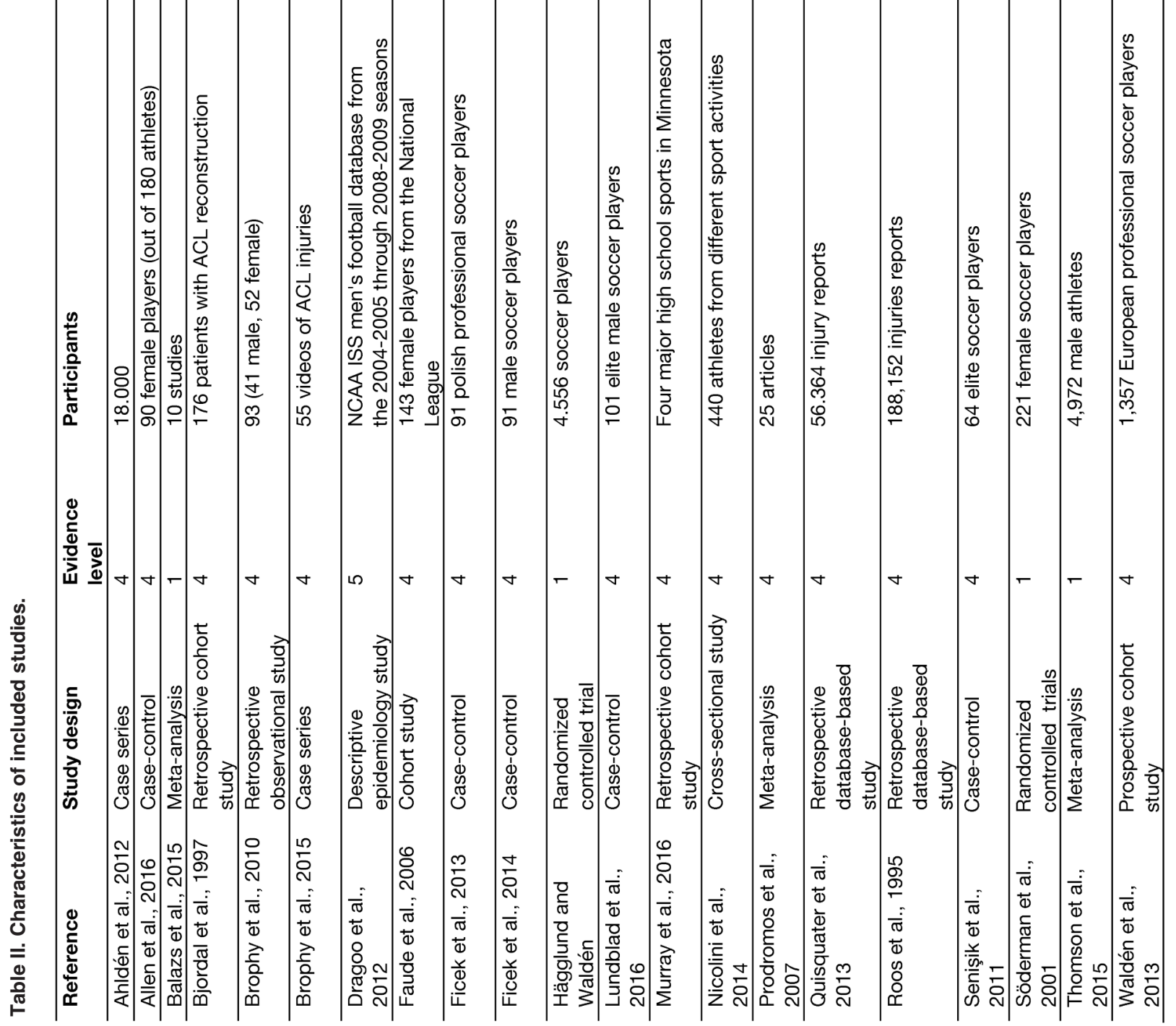
sway of the legs, hyperextension of the knee joint, and a low hamstring-to-quadriceps ratio during concentric action were factors associated with higher ACL injury rate. Mohamed et al. ${ }^{17}$ investigated ACL injury risk in U-23 female soccer players of South Africa, carrying out a case-control study, and found that anatomic factors such as Q-angle, pelvic width, and intercondylar notch were not predictor of ACL injury. Senişik et al. ${ }^{18}$ carried out a case-control study, recruiting 64 elite soccer players and 45 sedentary controls, and found that posterior tibial slope was a risk factor of $A C L$ injury.

\section{Genetic risk factors}

Ficek et al. ${ }^{19,20}$ examined the association of the collagen, type I, alpha 1 (COL1A1) -1997G/T and $+1245 \mathrm{G} / \mathrm{T}$ polymorphisms, both individually and as haplotypes, with ACL injury in 91 male Polish professional soccer players (aged $23 \pm 3$ years) with surgically diagnosed primary ACL ruptures versus 143 healthy soccer players. After collecting oral epithelial cells, the Authors found that polymorphisms haplotype was associated with reduced risk for ACL rupture (Hap.score -1.98, $p=0.048$ ). The same Authors investigated also whether the COL12A1 A9285G polymorphism was associated with $A C L$ ruptures in the same sample and found no relationship between COL12A1 polymorphism and risk of ACL injury. Without focusing on polymorphisms, Hägglund and Waldén ${ }^{21}$ performed a randomized controlled trial (RCT) recruiting 4,556 players aged 12-17 years and found that familial predisposition of ACL injury was significantly associated with ACL tear (HR 3.57 [95\% Cl 1.48-8.62]).

\section{Experience}

Being collegiate athletes exposes to higher ACL injury risks. Conversely, Roos ${ }^{10}$ et al. found that being elite players was a risk factor (OR 3.3 [95\% C 1.76.1]). According to the meta-analysis of Prodromos et al. ${ }^{14}$, the collegiate soccer tear rate was 0.32 for female players and 0.12 for male players.

\section{Training and competition effects}

Competition was a factor associated with ACL injury in several studies, such as in the study carried out by Quisquater et al. ${ }^{9}$. Dragoo et al. ${ }^{22}$ found that the risk during game was $10.09(95 \% \mathrm{Cl}, 8.08-12.59)$ times higher than the risk during practice. In its turn, considering more specifically practice, the injury rate was significantly greater during scrimmage compared with regular practice and walk-through. According to Murray et al. ${ }^{23}$, neuromuscular training could decrease ACL injury risk. Prodromos et al. ${ }^{14}$ performed a metaanalysis and found that neuromuscular training reduced the ACL tear incidence in soccer by 0.24 .

\section{Playing position}

Faude et al. ${ }^{24}$ found that injury incidence was higher in defenders (9.4 injuries per 1,000 hours exposure) and strikers (8.4/1000 hours) than goalkeepers (4.8/1000 hours) and midfielders (4.6/1000 hours).
Brophy et al. ${ }^{25}$ reviewed 55 videos of ACL injuries and found that most ACL injuries occurred when the opposing team had the ball and the injured athlete was defending (73\%). Females were more likely to be defending when they injured their ACL (87 versus $63 \%$ for males, $p=0.045)$. The most common playing action was tackling (51\%), followed by cutting (15\%). Most injuries occurred due to a contact mechanism (56\%) with no significant difference for sex. Females were more likely to suffer a noncontact injury in their left knee $(54 \%)$ than males $(33 \%)(p=0.05)$. Roos et al. ${ }^{10}$ found that playing in the forward position was associated with an OR of 1.8 [95\% Cl 1.4-2.5].

\section{Rural versus urban team}

Interestingly, Murray et al. ${ }^{23}$ found that playing in rural versus urban team was associated with a decreased risk of sustaining ACL injury.

\section{Dominant leg}

Faude et al. ${ }^{24}$ found that injury risk was higher for dominant legs, especially in case of contact injuries. Brophy et al. ${ }^{26}$ performed a retrospective observational study, assessing 93 soccer players (41 males, 52 females). When limited to a non-contact injury mechanism, half of the injuries occurred in the preferred kicking leg and the contralateral leg. When stratifying for gender, females were more likely to injure the ACL in their supporting leg, whereas males tended to injure their kicking leg (74.1 versus $32 \%$, $p<0.002)$.

\section{Sporting surface}

According to Dragoo et al. ${ }^{22}$ the rate of ACL injury on artificial surfaces was $1.39(95 \% \mathrm{Cl}, 1.11-1.73)$ times higher than the injury rate on grass surfaces. Balazs et al. ${ }^{27}$ performed a systematic literature review and synthesized 6 cohort studies. No increased risk of ACL ruptures when playing on synthetic surfaces was found.

\section{Shoe-surface interaction}

Thomson et al. ${ }^{28}$ performed a meta-analysis assessing whether higher shoe-surface interaction could represent a risk factor for ACL injury. They pooled together three prospective studies and obtained an OR of 2.73 [95\% Cl 2.13-3.15].

\section{Previous ACL injury}

Lundblad et al. ${ }^{29}$ performed a case-control study recruiting 101 elite male soccer players previously injured. History of ACL tears was not associated with a risk of being injured again in the 90 -day period after returning to play (OR 1.20 [95\% Cl, 0.66-2.17], $\mathrm{p}=0.65)$, as well as being absent for an ACL injury (OR 1.14 [95\% Cl, 0.64-2.01], $p=0.77$ ). Brophy et al. ${ }^{26}$ carried out a cohort study in 100 soccer athletes (55 males, 45 females) and found that females were more likely to have future ACL surgery (20 versus $5.5 \%, p=0.03)$, after re-injuring their $A C L$ or injuring their contralateral ACL. ACL reconstruction on the non-dominant limb was a risk factor for future ACL in- 
jury (16 versus $3.5 \%, p=0.03$ ). According to Ahldén et al. ${ }^{30}$, Faude et al. ${ }^{24}$ recruited 143 female soccer players from the German National League and found that the risk of a new $A C L$ rupture was increased in players with a previous rupture (OR 5.24, $p=0.01$ ). Allen et al. ${ }^{31}$ in a cohort of 90 female players found that returning to play after ACLR was associated with a higher risk of sustaining graft tears compared with those who did not return to soccer (15 versus $0 \%$, $p=0.04)$. However, there was no significant difference regarding contralateral ACL tears (19\% for returning players versus $9 \%$ for those who did not return, $\mathrm{p}=0.34$ ). From an etiopatogenethic standpoint, high ACL re-injury rate could be explained by:

1) a premature return to play; 2) an incorrect transition between rehabilitation period to training, which may cause an overloading of the neo-ligament tissues that are not healed or completely remodelled yet; 3) a high motivation of the athlete to show to the coach his/her full recovery, after being absent because of the injury, resulting in a high-intensity level of playing and, as a such, exposing himself/herself to re-injury; 4) an altered knee kinematics and a diminished proprioception; 5) other concomitant injuries at knee joint level; 6) a neo-ligament inclined lower than $50^{\circ}$ or higher than $60^{\circ} ; 7$ ) a bad placement of the tibial tunnel (that should be positioned at $40-45 \%$ of the tibial plateau); 8) a neo-ligament with an inclination lower than $50^{\circ}$ or higher than $60^{\circ}$ and 9) an aggressive playing style.

\section{Other factors warranting further investigations}

Waldén et al. ${ }^{32}$ found that ACL injury incidence was lower in the northern European teams with a statistically significant difference (rate ratio $0.43,95 \% \mathrm{Cl}$ 0.25 to 0.77 ), especially for noncontact ACL injury (rate ratio $0.19,95 \% \mathrm{Cl} 0.09$ to 0.39 ). ACL injuries may have climate or surface risk factors (possibly related to types and structure of grass and shoe-surface traction) that are universal across different football $\operatorname{codes}^{23}$.

\section{Conclusions}

Football represents a popular sport and $A C L$ injuries are quite common among football players. Despite the importance of such topic, the body of research exhibits a low-fair level of evidence. Only 1 study was a RCT. Further, whilst some risk factors have been highly studies and, therefore, are well-established in the etiopathogenetic framework of ACL rupture, for others the extant literature shows, instead, contrasting findings. Some findings, like regional differences among football players, warrant supplemental investigations. As such, further studies in the field are urgently needed.

\section{Conflicts of interest}

The Authors declare no conflicts of interest concerning this article.

\section{References}

1. Aglietti $P$, Giron F, Cuomo P. Anterior cruciate ligament injuries. In: Football Traumatology. Volpi P (Ed). Springer Edition. Springer-Verlag Italia, 2006;205-215.

2. Friel NA, Chu CR. The role of ACL injury in the development of posttraumatic knee osteoarthritis. Clin Sports Med. 2013;32 (1):1-12.

3. Roos H, Ornell M, Gärdsell P, et al. Soccer after anterior cruciate ligament injury: an incompatible combination? A national survey of incidence and risk factors and a 7-year follow-up of 310 players. Acta Orthop Scand. 1995;66:107-112.

4. Bjordal JM, Arnły F, Hannestad B, Strand T. Epidemiology of anterior cruciate ligament injuries in soccer. Am J Sports Med. 1997;25(3):341-345.

5. Faude O, Junge A, Kindermann W, Dvorak J. Risk factors for injuries in elite female soccer players. Br J Sports Med. 2006;40(9):785-790.

6. Giza E, Mithöfer K, Farrell L, Zarins B, Gill T. Injuries in women's professional soccer. Br J Sports Med. 2005;39(4):212216.

7. Alentorn-Geli E, Myer GD, Silvers HJ, et al. Prevention of noncontact anterior cruciate ligament injuries in soccer players. Part 1: Mechanisms of injury and underlying risk factors. Knee Surg Sports Traumatol Arthrosc. 2009;17(7):705-729.

8. Padulo J, Oliva F, Frizziero A, Maffulli N. Muscles, Ligaments and Tendons Journal - Basic principles and recommendations in clinical and field Science Research: 2016 Update. MLTJ. 2016;6(1):1-5.

9. Quisquater L, Bollars $\mathrm{P}$, Vanlommel L, Claes S, Corten K, Bellemans $J$. The incidence of knee and anterior cruciate ligament injuries over one decade in the Belgian Soccer League. Acta Orthop Belg. 2013;79(5):541-546.

10. Roos H, Ornell M, Gärdsell P, et al. Soccer after anterior cruciate ligament injury: an incompatible combination? A national survey of incidence and risk factors and a 7-year follow-up of 310 players. Acta Orthop Scand. 1995;66:107-112.

11. Bjordal JM, Arnły F, Hannestad B, Strand T. Epidemiology of anterior cruciate ligament injuries in soccer. Am J Sports Med. 1997;25(3):341-5.

12. Nicolini AP, De Carvalho RT, Matsuda MM, Sayum JF, Cohen $M$ Common injuries in athletes' knee: experience of a specialized center. Acta Ortop Bras. 2014;22(3):127-31.

13. Waldén $M$, Hägglund $M$, Magnusson $H$, Ekstrand J. Anterior cruciate ligament injury in elite football: a prospective three-cohort study. Knee Surg Sports Traumatol Arthrosc. 2011;19 (1):11-9.

14. Prodromos CC, Han Y, Rogowski J, Joyce B, Shi K. A metaanalysis of the incidence of anterior cruciate ligament tears as a function of gender, sport, and a knee injury-reduction regimen. Arthroscopy. 2007;23(12):1320-1325.

15. Benjaminse A, Otten E. ACL injury prevention, more effective with a different way of motor learning? Knee Surg Sports Traumatol Arthrosc. 2011;19(4):622-627.

16. Söderman K, Werner S, Pietilä T, Engström B, Alfredson H Balance board training: prevention of traumatic injuries of the lower extremities in female soccer players? A prospective randomized intervention study. Knee Surg Sports Traumatol Arthrosc. 2000;8(6):356-363.

17. Mohamed EE, Useh U, Mtshali BF. Q-angle, Pelvic width, and Intercondylar notch width as predictors of knee injuries in women soccer players in South Africa. Afr Health Sci. 2012;12 (2):174-180.

18. Senişik $S$, Ozgürbüz $C$, Ergün $M$, Yüksel $O$, Taskiran E, Işlegen C, Ertat A. Posterior tibial slope as a risk factor for anterior cruciate ligament rupture in soccer players. J Sports Sci Med. 2011;10(4):763-767. 
19. Ficek K, Stepien-Slodkowska M, Kaczmarczyk M, et al. Does the A9285G Polymorphism in Collagen Type XII a1 Gene Associate with the Risk of Anterior Cruciate Ligament Ruptures? Balkan J Med Genet. 2014;17(1):41-46.

20. Ficek K, Cieszczyk P, Kaczmarczyk M, et al. Gene variants within the COL1A1 gene are associated with reduced anterior cruciate ligament injury in professional soccer players. J Sci Med Sport. 2013;16(5):396-400.

21. Hägglund $M$, Waldén $M$. Risk factors for acute knee injury in female youth football. Knee Surg Sports Traumatol Arthrosc. 2016;24(3):737-746.

22. Dragoo JL, Braun HJ, Durham JL, Chen MR, Harris AH. Incidence and risk factors for injuries to the anterior cruciate ligament in National Collegiate Athletic Association football: data from the 2004-2005 through 2008-2009 National Collegiate Athletic Association Injury Surveillance System. Am J Sports Med. 2012;40(5):990-995

23. Murray JJ, Renier CM, Ahern JJ, Elliott BA. Neuromuscular Training Availability and Efficacy in Preventing Anterior Cruciate Ligament Injury in High School Sports: A Retrospective Cohort Study. Clin J Sport Med. 2016.

24. Faude O, Junge A, Kindermann W, Dvorak J. Risk factors for injuries in elite female soccer players. Br J Sports Med. 2006 40(9):785-790.

25. Brophy RH, Stepan JG, Silvers HJ, Mandelbaum BR. Defending Puts the Anterior Cruciate Ligament at Risk During Soccer: A Gender-Based Analysis. Sports Health. 2015;7(3):244-249.

26. Brophy R, Silvers HJ, Gonzales T, Mandelbaum BR. Gender influences: the role of leg dominance in ACL injury among soccer players. Br J Sports Med. 2010;44(10):694-697.

27. Balazs GC, Pavey GJ, Brelin AM, Pickett A, Keblish DJ, Rue JP. Risk of Anterior Cruciate Ligament Injury in Athletes on Synthetic Playing Surfaces: A Systematic Review. Am J Sports Med. 2015;43(7):1798-1804.

28. Thomson A, Whiteley R, Bleakley C. Higher shoe-surface interaction is associated with doubling of lower extremity injury risk in football codes: a systematic review and meta-analysis. Br J Sports Med. 2015;49(19):1245-1252.

29. Lundblad M, Waldén M, Hägglund M, Ekstrand J, Thomeé $C$ Karlsson J. No Association Between Return to Play After Injury and Increased Rate of Anterior Cruciate Ligament Injury in Men's Professional Soccer. Orthop J Sports Med. 2016;4 (10):2325967116669708.

30. Ahldén M, Samuelsson K, Sernert N, Forssblad M, Karlsson J, Kartus J. The Swedish National Anterior Cruciate Ligament Register: a report on baseline variables and outcomes of surgery for almost 18,000 patients. Am J Sports Med. 2012 40(10):2230-2235.

31. Allen MM, Pareek A, Krych AJ, et al. Are Female Soccer Players at an Increased Risk of Second Anterior Cruciate Ligament Injury Compared With Their Athletic Peers? Am J Sports Med. 2016;44(10):2492-2498.

32. Waldén M, Hägglund M, Orchard J, Kristenson K, Ekstrand $J$. Regional differences in injury incidence in European professional football. Scand J Med Sci Sports. 2013;23(4):424430. 